Martínez Ballester, José Juan.

Técnico de escultura, medios audiovisuales e imagen digital; Universitat Politècnica de València; Facultad de Bellas Artes de San Carlos; Departamento de escultura; Laboratorio de Creaciones Intermedia; Artxiviu de IHorta.

\title{
En los alrededores de la rotonda. Caso de estudio de un artista marginal
}

\section{Around roundabout. Case study of a marginal artist}

TIPO DE TRABAJO: Comunicación.

PALABRAS CLAVE

Arte marginal, art brut, pancartismo.

KEY WORDS

Outsider art, raw art, bannerism.

RESUMEN

El Arte Marginal, también conocido principalmente como Art Brut, Outsider Art o también Raw Art, forma parte de un grupo de manifestaciones artísticas poco o nada consideradas por el mundo del arte contemporáneo, invisibilizadas al fin y al cabo tanto por la crítica como por el público y, por supuesto, los propios artistas.

Se da la paradoja por otro lado de que en algunos de los lugares en los que tradicionalmente se exhibe el arte público contemporáneo oficial, es decir supuestamente aplaudido o por aplaudir, como por ejemplo puedan las rotondas de nuestras ciudades y carreteras, se llevan realizando intervenciones cuya firma y autoridad son más que discutibles, por no decir claramente desafortunadas.

Si bien estas ejecuciones tienen lugar en el centro de las rotondas, nosotros venimos desde hace tiempo ocupándonos y actuando sobre y como fenómenos que tienen lugar en sus alrededores, sus márgenes al fin y al cabo.

Como parte de estas acciones e investigaciones sacamos aquí a la luz el caso de, llamémosle 'Vicente' ("la víctima Vicente", en sus propias palabras'), un grafista que lleva años exhibiendo sus mensajes de auxilio pintados sobre cartones y tableros colocados en diversos puntos de la comarca de L’Horta de València, principalmente en carreteras y poblaciones de L'Horta Nord.

Fruto de nuestra investigación, mostraremos algunos de sus trabajos y ubicaciones, así como entrevistas en las que este artista heterógrafo nos narra cuáles son sus pulsiones y motivaciones, así como reflexiones e hipótesis al respecto.

\section{ABSTRACT}

The Marginal Art, also known mainly as Art Brut, Outsider Art or also Raw Art, is part of a group of artistic manifestations little or nothing considered by the world of contemporary art, invisible after all, both by critics and by the public and, of course, the artists themselves.

There is a paradox on the other hand that in some of the places where official contemporary public art is traditionally exhibited, that is supposedly applauded or applauded, such as the roundabouts of our cities and roads, interventions have been carried out whose signature and authority are more than debatable, not to say clearly unfortunate.

Although these executions take place in the center of the roundabouts, we have been occupying for a long time, occupying ourselves and acting on and as phenomena that take place in their surroundings, their margins after all. 
As a result of these actions and investigations we bring to light the case of, let's call it 'Vicente' ("the victim Vicente, in his own words"), a graphic designer who has been displaying his messages of help painted on cardboard and boards placed for years. in different points of the region of L'Horta de València, mainly on roads and towns of L'Horta Nord.

As a result of our research, we will show some of his works and locations, as well as interviews in which this heterograph artist tells us what his drives and motivations are, as well as reflections and hypotheses about them.

\section{INTRODUCCIÓN}

El Arte Marginal, también conocido principalmente como Art Brut (Arte Bruto), Outsider Art o también Raw Art, forma parte de un grupo de manifestaciones artísticas poco o nada consideradas por el mundo del arte contemporáneo, invisibilizadas al fin y al cabo tanto por la crítica como por el público y, por supuesto, los propios artistas.

Todas estas denominaciones se adaptan perfectamente a su significado, definen sin duda su contenido, aunque siempre podemos profundizar en su sentido. Art Brut, por ejemplo, no se refiere como podríamos pensar en arte 'a lo bruto', sino más bien al arte 'en bruto', tal y como lo traduce Cari Baena (1992) en la edición en castellano del clásico de Jean Dubuffet, El hombre de la calle ante la obra de arte; esto es, se trata de un sentido más bien de 'arte puro', sin tratar o mediatizar, sin cocinar, realizado por brutos, o lo que es lo mismo, sin educar, cerriles; e igualmente crudo, como resulta de uno de los sentidos de raw, lo que nos remite a las oposiciones entre cultura y naturaleza, procesado y no procesado que asentara Levi-Strauss (1986).

Outsider Art, o Arte Marginal, parece asimismo referirse al arte producido por personas marginales, fuera de la sociedad, y también enajenadas; sin embargo, también podemos entender, y así lo hacemos, que se trata de autores y autoras que se encuentran al margen del mundo del arte, en donde son precisamente y en todo caso minoritarias, y por ello exactamente debemos considerarlas como originales, en todos los sentidos que contiene esta palabra.

Es un hecho además que del mismo modo que el arte contemporáneo se apropia de métodos, procesos y conceptos de las artes populares, más conocidas generalmente como artesanías, igualmente se incorporan a los quehaceres artísticos profesionalizados -y a sus enseñanzas- técnicas, modos de hacer -y de ver- más característicos de las expresiones naif y autodidactas.

Se da la paradoja, por otro lado, de que en algunos de los lugares en los que tradicionalmente se exhibe el arte público contemporáneo oficial, es decir supuestamente aplaudido o por aplaudir, como por ejemplo puedan ser las rotondas de nuestras ciudades y carreteras, se llevan realizando intervenciones cuya firma y autoridad son más que discutibles, por no decir claramente desafortunadas. Si bien estas ejecuciones tienen lugar en el centro de las rotondas, nosotros venimos desde hace tiempo ocupándonos y actuando sobre y como fenómenos que tienen lugar en sus alrededores, sus márgenes al fin y al cabo.

\section{PINTAR EN DEFENSA PROPIA}

En los años 70, en la ciudad de València, caminaba por sus calles un personaje, probablemente enajenado, clamando a voz en grito "iSOCORRO!". Lo que se conoce comúnmente como un turulato, o lo que es lo mismo, quizás afectado por el síndrome de Tourette. Se le podía ver caminando por la calzada, sujetando a su lado una bicicleta en cuyo portaequipajes llevaba un bidón metálico.

Más tarde en esta misma ciudad, en los años 80 , se podía contemplar a otro actuante de espíritu completamente distinto que circulaba en bicicleta llamativamente ataviado, haciendo sonar diversos instrumentos como platillos o campanillas y con unos carteles en los que se podía, por ejemplo, leer lo siguiente: "YO CONTAMINO ALEGRÍA Y PAZ. QUE FLAMENCO VA EL TIO. PORQUESERA" o "HAGA FRIO O CALOR EN BICICLETA SE VIAJA MEJOR". Conocido como el "Tío Pepe", José García Ballester fue un mecánico y biciactivista que tenía un taller de bicicletas (Villa Quitapenas) en el barrio del Cabanyal, en València. Imágenes fotográficas del mismo pudieron verse en la exposición y correspondiente publicación del fotógrafo José García Poveda La València d’El Flaco (2017), mostrada en el Centre Cultural La Nau de la Universitat de València, así como también la muestra dedicada a este personaje en el teatro El Musical de València en 2018, Tío Pepe. Cabanyal.

Realizar proclamas a través de carteles, pancartas o pasquines es una actividad que se viene realizando desde tiempos inmemoriales, ya sea a nivel individual como colectivo, de forma anónima o pública y notoria, espontánea o planificadamente, e incluso con nocturnidad y alevosía. Se trata de un tipo de manifestación, además, que puede ser enclavada tanto dentro del mundo del arte, como de la política o la sociología, y que ha venido siendo realizada igualmente por gente que se aplica a ello de un modo generalmente poco perfeccionista. No olvidemos que, esencialmente, es un tipo de obra efímera, que responde a un uso y tiempo determinados, casi siempre manufacturado, lo que determina ese carácter improvisado incluso cuando es realizado por artistas profesionalizados. 
Nuestras primeras aproximaciones a este tema fueron publicadas en el póster del primer congreso de Investigadores en arte, El arte necesario (2013), PANCARTE2011. Allí, además de proponer una tipografía específicamente diseñada para pancartas, realizamos un recorrido de propuestas relacionadas con lo que entonces denominamos pancartismo a lo largo de la historia del arte y los artistas. Así mismo nos ocupamos de estas investigaciones en nuestra tesis Gramáticas de la heterografía: Trazado de propuestas propias e impropias alrededor de la escritura y la gráfica heteróclitas (2016), principalmente en el capítulo 6, Heterografías en movimiento: Breve historia del pancartismo. También investigamos sobre los pasquines y las Statue Parlanti, en nuestro comunicado para el II Congreso de la ANIAV, <real | virtual> Grafitos, pancartas, pasquines y otros relatos iconoclastas (2015).

Desde entonces, hemos seguido indagando, documentando y creando acciones y obras alrededor de estos temas. Como parte de estas acciones e investigaciones sacamos aquí a la luz el caso de, llamémosle 'Vicente' ("la víctima Vicente", en sus propias palabras), un grafista que lleva años exhibiendo sus mensajes de auxilio pintados sobre cartones y tableros colocados en diversos puntos de la comarca de L'Horta de València, principalmente en carreteras y poblaciones de L'Horta Nord.

\section{RONDANDO ROTONDAS}

Si circulamos por cualquier carretera, nos enfrentaremos desde ella a múltiples estímulos visuales y mensajes, sean estos intencionados o no. Vallas publicitarias, señales viarias, esculturas monumentales, cruces, murales e intervenciones públicas... La mayoría, o al menos las más provienen de corporaciones públicas y privadas (ayuntamientos, empresas, Tráfico y Obras Públicas, etc.). Sin embargo, también nos podemos encontrar con multitud de intervenciones y acciones realizadas por gente anónima que emplean estos mismos lugares superponiéndose a los mismos, alternando con ellos o simplemente situándose a su alrededor. Conocida es la querencia de los estamentos en colocarse en el centro de lo visible, pero existe una multitud, elevada a n, empeñada en tomar para sí su parte del protagonismo visual del espacio público. No solo hablamos de artistas callejeros supuestamente anónimos que firman con su nombre o seudónimo aquí y allá, sino de personas que tratan de mandar un mensaje a través de los medios que se tienen más a mano y en los espacios que les producen mayor impacto visual en los lugares de máximo tránsito. Desde puestos de venta de productos hortícolas a autoestopistas con su destino en una cartela; pendones en los balcones (balconadas) con protestas sobre los más diversos temas vecinales y sociales, mayoritaria y precisamente sobre los problemas principalmente sonoros ocasionados por el exceso de circulación de personas y vehículos, o como se ha visto recientemente: banderas nacionalistas en reivindicaciones soberanistas, lazos de cualesquiera colores según la reivindicación pertinente, etc.

En nuestro caso, si paseamos o circulamos por la periferia de la ciudad de València, nos podemos encontrar con una serie de carteles realizados sobre soportes diversos y colocados junto a las calzadas de l'Horta Nord. Igualmente, aunque con menor presencia, los hemos podido encontrar en otros puntos de la comarca de l'Horta, incluso los hemos encontrado en el centro de sus poblaciones. Están realizados sobre puertas, cartones, trozos de táblex o contrachapado... a los que se le aplica una primera imprimación blanca o al menos clara sobre la que más tarde se inscriben los mensajes. Los dibujos suelen ser casi siempre de figuras humanas, en una antropomorfía muy elemental: un círculo sobre un rectángulo suele bastar; pero también y principalmente motocicletas, aviones, helicópteros, trenes o camiones y autos con sirena como por ejemplo ambulancias: vehículos ruidosos al fin y al cabo; igualmente campanas, unas estructuras que semejan altavoces o emisores sónicos; también algunos signos que representan las emisiones de ruido en forma de puntitos emitidos por estos vehículos. Por otro lado, los textos, siempre en mayúsculas, hacen generalmente alusión a las torturas de que el autor se siente víctima a causa de todos estos sonidos: detenido, crimen, ejecutando con ambulancias, ruido, odio, aviones, motos, sirenas, campanas, día y noche, sin descanso, basta de asesinatos, secretas intentándolo con el metro, etc. También hace ocasionalmente alusiones a los lugares en que ejecuta o sitúa sus obras lugares como este que reza: LLEVO VALENCIA BURJASOT MONCADA ROCAFORT Y GODELLA"

Toda una década hace que periódica y sistemáticamente vengan apareciendo y nosotros documentando (desde 2011) estas imágenes delirantes. Lo hicimos inicialmente por curiosidad o un interés todavía indefinido, pero progresivamente en aumento, dedicándole un pequeño apartado en nuestra tesis, lo que nos indujo a proceder de una manera más seria y sistemática nuestra investigación. Así fue como iniciamos, además de la labor de archivo y documentación, la de su búsqueda para la realización de una entrevista. Empero, el autor resultaba tremendamente escurridizo. Inicialmente llegamos por fin a localizar dos lugares que podríamos calificar como sus 'estudios', cerca de donde más profusión había de sus producciones. Uno en el barrio de Benicalap de València, cerca de la Ciudad Fallera y otro en la huerta de Godella. Se tratan en realidad de un rincón acotado entre malas hierbas y de un espacio al pie del muro de un convento. Allí el autor hace acopio de soportes, pinturas, agua, botes, brochas, rodillos y demás enseres que le son necesarios para llevar a cabo sus obras. Tras muchas horas empleadas en esperas cerca de estos dos lugares, inquisiciones a vecinos, agricultores y merodeantes, cámaras ocultas y demás pérdidas de tiempo logramos por fin encontrarnos con él, acorralarle literalmente al borde de la Real Acequia de Moncada y grabar una conversación entre ambos.

No podemos decir que se trate de una buena entrevista, relajados y cómodos, en la que el entrevistado se encuentra libre y feliz de exponer sus ideas mientras el entrevistador permanece callado, sin robarle protagonismo, y dejando fluir sus pensamientos en forma verbal; con la cámara sobre un trípode y la iluminación adecuadamente controlada. Más bien al contrario. Venía caminando por el borde de la acequia, en un punto en que esta tiene dos metros de ancho y alto, de entre los que seguro que más de uno sería de profundidad. En cuanto nos vio, lo primero que hizo fue darse media vuelta y a duras penas le logramos alcanzar a base de gritos y 
aspavientos para que se detuviese. Tomando cámara en mano, tras unos inicios afables en los que pedirle permiso, en una zona sombría y haciendo equilibrios para no caer al agua, logramos extraer algo de información de una persona más esquiva aún en sus palabras que en su presencia. Aun así, logramos realizar una suerte de entrevista en la que antes que hacer preguntas, más tratábamos de evitar que saliera por piernas. Aunque le emplazáramos a posteriores reuniones, siempre ha resultado informal, y solo podemos, de momento, ofrecer los resultados de aquel encuentro: https://vimeo.com/152602390.

De nombre Vicente, "Vicente, la víctima del estado", según sus propias palabras vive en algún sitio indeterminado de l'Horta Nord: "Yo estoy escondido. Yo vivo en un sitio escondido, me tengo que esconder de ellos. Donde no me puedan rodear. (...) Cerca, cerca es una amplia zona. Yo estoy por aquí por esta zona, amplia, por todos estos campos. Estoy por acá pero no te voy a decir dónde estoy escondido. (...) No puedo estar en las ciudades ni na porque me rodean ahí con las sirenas tengo que esconderme de ellos tengo que huir de ellos. (...) Pero es una amplia zona en la que estoy por acá. Burjassot, Torrefiel..."

Las motivaciones de su trabajo no pueden ser más tajantes: "una defensa propia; no soy artista ni nada de eso, hombre" y según parece comenzó con ello durante algún momento de la Guerra de Irak (2003-2011). Este consiste, en definitiva, en ir moviendo sus afiches por toda la huerta, repintándolos y cambiándolos: "Hombre yo también los quito; yo quito y pongo. Yo los quito y a lo mejor me tiro una semana sin ponerlos y los vuelvo a poner otra vez. (...) Pero que ahora iba a quitar otra vez y lo iba a pintar ese de blanco y mañana pues ya no sé cuándo me toquen ya pongo otra cosa".

En nuestra conversación con él, razonaba igual que en sus textos y dibujos acerca de lo que le mueve a realizarlos: "Es que voy cambiando los carteles. Según me hacen en un día los voy cambiando. Lo que más hacen en un día lo pongo. Por ejemplo hoy me han torturado con aviones ¿no?, pues he puesto aviones. Y hoy hay coches de policía (...) todos los días no, todos los días no puedo. Es que no lo sé yo cuándo voy a hacerlo. Es cuando me cargo mucho. Cuando ya me cabreo mucho, ya los pinto y los pongo. si me torturan mucho ese día los pinto y los pongo, pero si no, no. (...) Así como hoy ha sido un día más o menos tranquilo. Solo he oído unas campanadas, un avión que ha pasado y ya está y un coche de policía y ya está hoy".

Como puede verse, el detonante de su frenética actividad suele ser, por un lado, la molestia que le producen los sonidos de sirenas, pitidos de automóviles, ruidos de motores, pero por otro también cabe destacar su obsesión con las estelas que en el cielo trazan los aviones. Afirma que lo hacen con algún sentido: "Cuando esté despejado miras al cielo y verás a los aviones haciendo rayas; que es que por donde voy me van haciendo rayas, rayas y cruces con aviones de vapor, me van haciendo rayas. No sé qué traman con las rayas, de no ser que traten de dejarme el cerebro en blanco".

Y cualquier cosa menos en blanco; ni el cerebro ni nuestra historia, ni el lienzo ni el verbo. Algo ocurre que nos insta a salir de nosotros mismos y llenar de significado, de trazas nuestro entorno; y esta pulsión es la misma en un artista marginal que en artista consagrado. "Tan solo pretendemos establecer un vínculo entre nosotros y el mundo, el momento de contacto entre el carbón y el muro, la tiza y la pizarra, la huella y la arena, el rotulador y el cartón son nuestros puntos de unión con el universo: la línea que trazamos no es de separación, sino de comunión" (Martínez, 2015), aunque ciertamente es tan vaporosa como las estelas de vapor que un avión genera en el cielo.

\section{FUENTES REFERENCIALES}

AA. VV. (2017). La València d'El Flaco. València: Universitat de València.

AA. VV. (2006). Art Brut. Genio y delirio. Madrid: Círculo de Bellas Artes.

Medem, J., Barrera, L. y Peñafiel, I. (productores) y Barrera, L. y Peñafiel, I. (directores). (2007). ¿Qué tienes debajo del sombrero? [Vídeo documental] España: Alicia produce.

De Certeau, M. (2007). La invención de lo cotidiano. 1. Artes de hacer. México: Universidad Iberoamericana.

Dubuffet, J. (1975). Escritos sobre arte. Barcelona: Barral.

Dubuffet, J. (1992). El hombre de la calle ante la obra de arte. Madrid: Debate.

Jouannais, J.-Y. (2009). Artistas sin obra. "I would prefer not to". Barcelona: Acantilado.

Levi-Strauss, C. (1986). Mitológicas. I, Lo crudo y lo cocido. México: Fondo de Cultura Económica. 
Martínez Ballester, José Juan

En los alrededores de la rotonda. Caso de estudio de un artista marginal

IV Congreso INTERNACIONAL DE INVESTIGACIÓN EN ARTES VISUALES ANIAV 2019

IMAGEN [N] VISIBLE]

http://dx.doi.org/10.4995/ANIAV.2019.9383

Peiry, L. (2001). L'Art Brut. París: Flammarion.

Martínez Ballester, J. J. (2013). PANCARTE2011. En: E. M. Pérez García (Dir.), I Congreso Internacional de Investigación en Artes Visuales. El arte necesario. La investigación artística en un contexto de crisis. València: Facultat de Bellas Artes UPV.

Martínez Ballester, J. J. (2015). Grafitos, pancartas, pasquines, estatuas parlantes y otros relatos iconoclastas. En: E. M. Pérez García (Dir.), II Congreso Internacional de Investigación en Artes Visuales. <real/virtual>. València: Facultat de Bellas Artes UPV.

Martínez Ballester, J. J. (2016). Gramáticas de la heterografía: Trazado de propuestas propias e impropias alrededor de la escritura y la gráfica heteróclitas (tesis doctoral). Universitat Politécnica de València, València.

Mitchell, J. (2000). El secreto de Joe Gould. Barcelona: Anagrama.

Rhodes, C. (2002). Outsider Art: alternativas espontáneas. Barcelona: Destino.

Torrico Cuadrado, E. (2018). Estatuas que hablan. Antología de pasquines sobre España. Madrid: Sílex.

Tuchman, M., Eliel, C. S. (1993). Visiones paralelas: Artistas modernos y arte marginal. Madrid: Museo Nacional Centro de Arte Reina Sofía.

Weinstock, Ch., Alexander, E. W. y Tucci, S. (productores), Tucci, S. (Director). (2000). El secreto de Joe Gould. EE. UU.: Laurenfilm.

Volpe, D. (2013). Arte Outsider: Aproximación a la construcción artística de las manifestaciones creativas al margen del sistema del Arte. Barcelona: Universidad Pompeu Fabra. 